\title{
Relationship between dietary intake in children with diabetes mellitus type I, their management at diagnosis, social factors, anthropometry and glycaemic control
}

\author{
Gun Forsander', Bertil Malmodin², Christina Eklund ${ }^{3}$ and \\ Bengt Persson ${ }^{4}$
}

\footnotetext{
'Department of Paediatrics, Division of Diabetes, The Queen Silvia Children's Hospital, Göteborg, ${ }^{2}$ Department of Internal Medicine, Falun Hospital, Falun, ${ }^{3}$ Department of Paediatrics, Uppsala University Hospital, Uppsala, and

${ }^{4}$ Department of Paediatrics, Karolinska Hospital, Stockholm, Sweden
}

\section{Abstract}

Background: In diabetes mellitus, dietary intake is important for metabolic control and contributes to the risk of developing microvascular and macrovascular complications. Little is known about factors influencing dietary intake.

Objectives: To ascertain the long-term influence of two initial programmes of treatment of diabetes mellitus type $\mathrm{I}$ in children and adolescents on dietary intake and to compare with dietary recommendations. To examine for correlations with social factors, anthropometry and glycaemic control.

Design: Children, 3-15 years of age, were chosen at random to be treated either in a paediatric ward (the control group) or, partly, in an apartment where their families were provided with extra psychological support and practical education (the study group). A prospective dietary assessment of 34 children with diabetes mellitus was performed, using 4 day food diaries at 6, 12 and 24 months after diagnosis.

Results: Both management groups complied well with the dietary recommendations, showed stable nutritional habits during the first 2 years after diagnosis and had favourable intake concerning fat and carbohydrates compared with healthy children. The study group demonstrated less day-to-day variation in their consumption of polyunsaturated fat. Few dietary correlations to social factors were shown. There were no significant correlations between dietary intake and age or gender. High long-term $\mathrm{HbA}_{1 \mathrm{c}}(>8.3 \%, 5$ years) was significantly associated with a higher intake of total fat, and more pronounced day-to-day variation in energy, carbohydrates and polyunsaturated fat.

Conclusions: Both treatment programmes appear well suited for establishing and maintaining recommended dietary intake. The home-like environment of the training apartment made it possible to illustrate the dietary customs of the child and family, and permitted an individual nutritional education with behaviour modification. The importance of the quantity and quality of fat consumed must be emphasized strongly.

Keywords: children; diet; glycaemic control; insulin-dependent diabetes mellitus (type I); management regimen; social factors

Received: 7 Jan 2003; Revised: 2 Apr 2003; Accepted: 7 Apr 2003

\section{Introduction}

For children and adolescents with diabetes mellitus, dietary intake is important for metabolic control, as well as contributing to the future risk of developing microvascular (1) and macrovascular complications (2). In this connection dietary recommendations have changed considerably since the early 1980s, now favouring the intake of more carbohydrate and less protein and fat $(3,4)$. The importance of fibre intake (3) and the type of the fat consumed have also been emphasized (5). A diet low in protein may protect the kidneys by decreasing the glomerular 
filtration rate, regardless of the level of glycaemic control (6). Other studies support the idea that the nature of the protein consumed is of significance in connection with renal protection (7).

Dietary intake, as regards the quantity and quality of protein, fat and carbohydrate consumed, might be influenced by the information and dietary education provided to the child, adolescent and family at the time of diagnosis of diabetes, as well as by the age and gender of the child, the family situation and the surrounding society (8).

Dietary habits are established very early in life and there is presently little information available on the impact of the initial treatment of diabetes and various pedagogical approaches on these habits (9). Children with diabetes whose families exhibit an unfavourable eating pattern at the time of diagnosis may have difficulties in adjusting to prescribed dietary recommendations. Dietary change is based on both knowledge and behavioural change and the dietary education model should reflect this. Intervention in the family's dietary habits is therefore a serious matter and, if deemed necessary, best carried out at the time of diagnosis. However, hospitalization of the child makes it difficult to observe the dietary customs of the family. Furthermore, outpatient care at the time of diagnosis may also hinder medical personnel from assessing these habits and intervening if required.

This prospective, randomized study compared various aspects of conventional initial treatment for diabetes at a hospital ward with partial care outside the hospital with extra family support and a problem-based learning system in a nearby apartment. The conditions of the control and study group have been discussed in detail previously (10). The programme theory that served as the basis of this study may be described as a nonhierarchical, multidisciplinary approach to care, an approach to the family based on systems thinking, a therapeutic environment, and problem-based learning.

The aims of this study were, first, to ascertain the long-term influence of these two different types of initial management regimen on dietary intake and to compare these against recommendations; and secondly, to look for possible correlations between dietary intake and social factors, age, gender, anthropometry and glycaemic control.

\section{Methods}

\section{Patients and procedures}

Over a period of 2 years and 9 months, 51 children were diagnosed as having diabetes mellitus in Dalarna, a region in central Sweden. Of these 51 children, 41 exhibited the criteria established for inclusion in this study, i.e. being 3-15 years of age at the time of diagnosis, living in Swedish-speaking families with their permanent guardians and not being treated for any other serious illness. Of these 41 families, $38(93 \%)$ agreed to participate and were followed prospectively.

The children were assigned randomly to receive either conventional hospital care (control group) or early discharge, together with the entire family, to an apartment close to the paediatric clinic (study group). The children were also grouped according to their age at diagnosis, i.e. 3-7.99 years of age (groups $\mathrm{C} 1$ and $\mathrm{S} 1$ ) or 8-14.99 years of age (groups $\mathrm{C} 2$ and S2). Initially, all of the patients were hospitalized and the patients in the control groups remained on the hospital ward (except for short stays at home) throughout the initial period of treatment and education.

In the conventional model the patient's treatment and the family's education were undertaken on a ward at the paediatric clinic, with usually one parent staying with the child day and night. Crisis support was performed generally by the social worker, but also by doctors and nurses in separate conversations and while handling everyday problems on the ward. Both parents were encouraged to take part in sessions of diabetes education according to a predetermined schedule. These were generally given separately by doctors, nurses and dietician. Discussions on treatment took place in informal meetings of the team and in ordinary meetings on the ward. The families received theoretical dietary information and were served a routine hospital diet. Family responsibility for care was put into practice during periods of home leave and after discharge.

In the study model there was an early discharge from the ward to a training apartment close to the hospital as soon as the child achieved satisfactory metabolic balance and the parents had learnt how to inject insulin and cope with hypoglycaemia. The whole family, including parents, brothers and sisters and sometimes grandparents, but no staff, stayed at the apartment for the remaining period of treatment. Active crisis support was given to the family 
by a psychotherapist and the diabetes team. Both parents were able to take sick leave according to Swedish law. Therapy was also focused on brothers and sisters and their reactions. Interventions, if necessary, were made based on system theory methods concerning ways of handling fear of injections, refusal to eat, relationship problems in the family, etc. The family acquired knowledge through different channels in the training apartment by seeking coping strategies in everyday situations and discussing them with the team. Advice concerning diabetes care given by the team was based on the assessment of individual needs and abilities within the family. The team was responsible for giving each family basic information, mainly by active dialogue concerning current problems. The members of the multiprofessional team visited the family in the training apartment by agreement, leaving several hours every day for the family's private life. The team visited in pairs, e.g. paediatrician and dietician, or psychotherapist and nurse. The problems could then be viewed from different perspectives. The team members behaved as consultants to active, competent people, avoiding an authoritarian attitude towards the family. The parents did the cooking for the family and chose what to serve in an active discussion with the dietician. New experiences relating to diet, including adaptation and practical and theoretical instruction, took place in a variety of day-to-day situations. The study group thus received extra help in developing dietary habits consistent with both individual and family life and the nutritional demands involved in managing diabetes.

A formal team conference was held before the family moved from the hospital to the apartment and thereafter regularly every fifth day until discharge. At the conference the metabolic condition of the child was discussed, as well as the illness in the context of the family history and the current situation.

Individualized dietary recommendations were established for the patients in both groups, all based on the official Swedish Nutrition Recommendations (SNR) for all children, similar to the recommended daily allowances (RDA) at the time of the study. These recommendations were derived from an early history of the children's diet, involving calculation of the total energy requirements and a semiquantitative determination of carbohydrate intake. Advice concerning consumption of fibre, sucrose and sugar-free products, and quality and quantity of fat and protein was given. Written and oral information was also provided to all families, daycare centres and schools involved.

During the first 2 years of this study all of the patients received three insulin injections per day and, thereafter, most of them were put on a regimen of multiple injections (four or more per day).

\section{Data collection}

Dietary record

The procedure for recording dietary intake was initially taught and trained by an experienced dietician during the first week after diagnosis. Some of the families chose to weigh the food, but most of them used other recommended measurements. The nutritionist checked the reliability of the recordings by using test meals. At 6, 12 and 24 months after diagnosis, the families recorded the daily food intake of their children for a period of 4 days in a food diary, i.e. 12 days altogether. A computer analysis of the dietary record was performed (Kostsvar; Aivo, Livsmedelsverket). The days on which the dietary intake was to be recorded included three weekdays and one weekend day (Saturday or Sunday). The use of multivitamin or mineral supplements was not taken into account. Extra meals, in excess of the six meals scheduled daily, mainly in connection with episodes of hypoglycaemia, were recorded separately. Nutrient composition was analysed with respect to total energy intake and contents of carbohydrate, fibre, protein and fat. The fat content was determined as the percentage of the total energy intake in the form of saturated fat, monounsaturated fatty acids and polyunsaturated fatty acids, as well as the daily intake of cholesterol. Since it has been reported that the levels of vitamins $\mathrm{D}$ and $\mathrm{E}$, as well as of zinc, may be insufficient in diabetic patients, these nutrients were also computed (11). Extra meals were usually consumed in connection with hypoglycaemic episodes and are regarded as possible negative indicators with regard to the dietary situation and body weight.

Social variables

Since an association has been observed between certain social factors and poor glycaemic control (12), the dietary intake of children living in a singleparent family and/or with parents having a low level 
of formal education were compared separately to the diets of the other children.

\section{Anthropometric measurements}

Each child's pubertal status was assessed using the procedure of Marshall and Tanner (13, 14). Body mass index (BMI) was calculated as weight $(\mathrm{kg}) /$ length ${ }^{2}\left(\mathrm{~m}^{2}\right)$. Since the reliability of the BMI as a measure of relative fatness has been questioned (15), skinfold thickness was also used as an estimation of body fat for comparison with dietary fat intake and glycaemic control. Skinfold at the biceps, triceps and subscapula on the right side of the body was measured three times using a Harpenden calliper by the same examiner at the time of diagnosis and 6,12 and 24 months later, and the mean value recorded to the nearest $0.1 \mathrm{~mm}$. According to earlier anthropometric studies, the sum of triceps and subscapular skinfold can be used as an indicator of body fat content. Therefore, these measurements were used in calculations involving children more than 7 years of age (16).

\section{Glycaemic control}

The major fraction of glycosylated haemoglobin $\left(\mathrm{HbA}_{1 \mathrm{c}}\right)$ was determined by high-pressure liquid chromatography (HPLC), with values of $3.5-5.3 \%$ being considered normal. The stability of these measurements over time was assured by quality assurance tests (SEQLA) and it was thus not necessary to use a correction factor (17). $\mathrm{HbA}_{1 \mathrm{c}}$ was determined every month during the first 2 years after diagnosis and, thereafter, every second or third month (18). From these values the annual means were calculated.

The degree of glycaemic control at the time of the 5 year follow-up was defined as the mean $\mathrm{HbA}_{1 \mathrm{c}}$ value during year 5 after diagnosis, based on at least four $\mathrm{HbA}_{1 \mathrm{c}}$ values during that year. Glycaemic control was classified as "good" when this mean $\mathrm{HbA}_{1 \mathrm{c}}$ value was $<6.4 \%$, "medium" when this value was $6.4-8.3 \%$ and "poor" when it was > $8.3 \%$. To test for possible correlations between long-term glycaemic control and dietary intake (documented as described above), the intake during the first 2 years following diagnosis were compared with the individual's glycaemic control 2 and 5 years after diagnosis. Problems in maintaining satisfactory glycaemic control start very early in children who exhibit poor control (defined as a mean $\mathrm{HbA}_{1 \mathrm{c}}$ value $>8.3 \%$ in the fifth year after diagnosis) (19).
The correlation between the individual mean $\mathrm{HbA}_{1 \mathrm{c}}$ value during the second year after diagnosis with the corresponding value during the fifth year was highly significant $(p<0.01)$. The children with a mean $\mathrm{HbA}_{1 \mathrm{c}}$ value $>8.3 \%$ during this fifth year constituted $20 \%$ of the total population and were compared nutritionally with the children exhibiting more favourable glycaemic control.

Each patient and family was recruited following informed consent and individual agreement to participate in the study. This study was approved by the local ethics committee.

\section{Statistical analysis}

The Student's $t$-test was used to compare the equality of means. The day-to-day variations in the recorded intake of nutrients were calculated using Levene's test for equality of variance (20). The Pearson correlation, a two-tailed test, was used to examine possible correlations between certain nutrients and glycaemic control. A multiple regression analysis was performed to relate BMI and body fatness to different variables. Correlations involving the number of extra meals consumed were analysed by the Spearman rank correlation test. A $p$-value of $\leq 0.05$ was considered statistically significant.

\section{Results}

The 26 girls and 12 boys included in this study had a median age of 9 years (range 3.0-14.0 years) at the time of diagnosis. Reliable dietary records were obtained for 34 of the 38 children, with one such record missing for one child in each of the four groups $(\mathrm{C} 1, \mathrm{C} 2, \mathrm{~S} 1, \mathrm{~S} 2)$. It was thus necessary to exclude these latter patients from the study. The reliable dietary information was based on dietary recording of a total of 2530 meals, with approximately 74 meals (range 46-102) being registered for each patient. All but three of the remaining 34 patients supplied reliable records on all three occasions, i.e. 4 days each at 6,12 and 24 months following diagnosis. These other three patients provided acceptable dietary records either at 6 and 12 months (two patients) or at 6 and 24 months (one patient) after diagnosis and could therefore be included. The total number of full eligible days recorded was 396.

Total treatment time is shown in Table 1. There was no significant difference in the time invested in both groups by the different members of the diabetes team, except for the dietician. A time 
Table I. Number of days spent in the hospital or apartment by patients and their families after diagnosis

\begin{tabular}{lrlll}
\hline & $\boldsymbol{n}$ & Hospital (days) & Apartment (days) & Total days \\
\hline $\mathrm{S1}$ & 7 & $12.3 \pm 5.4(7-20)$ & $11.3 \pm 2.1(8-14)$ & 23.6 \\
$\mathrm{C} 1$ & 7 & $22.0 \pm 5.3(16-30)$ & 0 & 22.0 \\
$\mathrm{~S} 2$ & 12 & $9.2 \pm 2.3(7-14)$ & $11.8 \pm 3.0(7-17)$ & 21.0 \\
$\mathrm{C} 2$ & 12 & $19.4 \pm 2.7(16-25)$ & 0 & 19.4 \\
\hline
\end{tabular}

Data are shown as mean \pm SD (range)

There were no significant differences between the groups regarding the total treatment time.

analysis revealed that the dietician spent significantly more time with the families of the study groups (Table 2). The mean height and weight of the patients did not differ from those of healthy children. One 14-year-old girl had a BMI of 24.5, while four other children between the ages of 12 and 14 years had BMI values of $22-24$. One prepubertal 11-year-old girl was very thin, although not ketotic, at the time of diagnosis, with a BMI value of 12.5 , but her later rate of growth was within the normal range. Three years after diagnosis, 13 of the 38 patients $(34 \%)$ had not begun to menstruate or, in the case of boys, reached Tanner stage 4 . Five years after diagnosis this value was three of $38(8 \%)$. BMI was significantly correlated with body fat $(p<0.01)$, expressed as the equation developed by Slaughter et al. (16). There was a very strong correlation for children at all ages in this study between body fatness expressed according to the Slaughter equation and the simpler sum of the skinfolds at the triceps and subscapularis.

The mean daily insulin dose was the same for the different age groups, i.e. $1.0 \mathrm{U} \mathrm{kg}^{-1}$ body weight 5 years after diagnosis. The insulin dose was, however, significantly lower $\left(0.85 \mathrm{U} \mathrm{kg}^{-1} \mathrm{day}^{-1} ; p<0.05\right)$ in patients exhibiting a mean $\mathrm{HbA}_{1 \mathrm{c}}$ value of $<6.4 \% 5$ years after diagnosis than in patients with corresponding values of $6.4-8.3 \%\left(1.1 \mathrm{U} \mathrm{kg}^{-1} \mathrm{day}^{-1}\right)$ or $>8.3 \%\left(1.0 \mathrm{U} \mathrm{kg}^{-1} \mathrm{day}^{-1}\right)$.

Table 2. Time (minutes) spent with each professional during hospital and apartment stay

\begin{tabular}{llll}
\hline Time with & Study group & Control group & $\boldsymbol{p}$ \\
\hline Paediatrician & $482(345-585)$ & $440(280-575)$ & $\mathrm{ns}$ \\
Dietician & $538(370-685)$ & $480(370-630)$ & $<0.05$ \\
Social worker & $126(60-355)$ & $119(60-250)$ & $\mathrm{ns}$ \\
Psychotherapist & $157(50-420)$ & 0 & \\
\hline
\end{tabular}

Data are shown as mean (range).

\section{Comparison of dietary intake between control and study groups}

The mean daily intake of protein, fat and carbohydrates in both the $\mathrm{C}$ and $\mathrm{S}$ groups was within normal ranges compared with the SNR provided (Table 3). The total mean daily energy intake (1975 kcal, 8.26 MJ) was lower than expected in all groups, although not statistically different between the groups. There were no statistically significant differences between the $\mathrm{C}$ and $\mathrm{S}$ groups.

The day-to-day variations between the groups in ingested nutrients differed in certain aspects. There were statistically significant differences in this variation for polyunsaturated fat $(p=0.015$, control $>$ study groups), linoleic acid (C18:2; $p=0.019$, control $>$ study groups), disaccharides $(p=0.013$, control $<$ study groups) and folacin $(p=0.042$, control $<$ study groups).

\section{Dietary intake in relation to the parents' social situation}

The social and educational situation of the families was described in detail previously (12). Surprisingly, children with more highly educated mothers had a higher content of saturated fat in their diet than the other children $(p=0.03)$, but this difference did not

Table 3. Mean daily intake of protein, fat and carbohydrates for children 6,12 and 24 months after diabetes diagnosis, in relation to the initial management programme and age

\begin{tabular}{|c|c|c|c|c|}
\hline & \multicolumn{2}{|c|}{ 3-8 years old } & \multicolumn{2}{|c|}{8 - I5 years old } \\
\hline & $\begin{array}{l}\text { Control group } \\
(n=6)\end{array}$ & $\begin{array}{l}\text { Study group } \\
(n=6)\end{array}$ & $\begin{array}{l}\text { Control group } \\
(n=1 \mathrm{I})\end{array}$ & $\begin{array}{l}\text { Study group } \\
(n=I I)\end{array}$ \\
\hline \multicolumn{5}{|c|}{ Protein, $g(E \%)$} \\
\hline 6 months & $66(15)$ & $60(15)$ & $88(17)$ & $84(16)$ \\
\hline 12 months & $64(14)$ & $63(15)$ & $79(16)$ & $83(16)$ \\
\hline 24 months & $65(15)$ & $71(16)$ & $84(16)$ & $83(15)$ \\
\hline \multicolumn{5}{|l|}{ Fat, $g(E \%)$} \\
\hline 6 months & $66(34)$ & $54(31)$ & $79(34)$ & $77(33)$ \\
\hline 12 months & $66(34)$ & $59(32)$ & $74(33)$ & $78(33)$ \\
\hline 24 months & $64(33)$ & $67(33)$ & $84(35)$ & $80(33)$ \\
\hline \multicolumn{5}{|c|}{ Carbohydrates, g (E\%) } \\
\hline 6 months & $222(5 \mathrm{I})$ & $207(54)$ & $258(49)$ & $264(5 \mathrm{I})$ \\
\hline 12 months & $229(52)$ & $216(53)$ & $259(51)$ & $265(5 I)$ \\
\hline 24 months & $224(52)$ & $230(5 \mathrm{I})$ & 261 (49) & $274(52)$ \\
\hline
\end{tabular}

The intake values were determined over a period of 4 days on each occasion. According to the Swedish Nutrition Recommendations at the time of the study, the percentage of total energy intake $(E \%)$ should be $15-18 \%$ for protein, $30-35 \%$ for fat and $50-55 \%$ for carbohydrates.

There were no statistically significant differences between the groups. 
significantly influence body fatness. The level of the fathers' formal education did not affect the dietary situation. Irrespective of age, children of single parents had a significantly higher body content of fat than the other children $(p=0.016)$ (Table 4), although there were no differences in the recorded dietary intake.

\section{Dietary intake in relation to gender, age and anthropometry}

When nutrient intake was expressed as $E \%$ or per $1000 \mathrm{kcal}(=4.18 \mathrm{MJ})$ there were no demonstrable differences in the dietary regimens of boys and girls or of younger (3-8 years old at the time of diagnosis) and older patients (8-15 years old). The mean daily intake of sucrose appeared to be lowest among the youngest children in the study group $\left(10 \mathrm{~g} \mathrm{day}^{-1}\right.$, compared with $18.3 \mathrm{~g} \mathrm{day}^{-1}$ in the age-matched control group), but this difference was not statistically significant. The mean \pm SD value for daily sucrose consumption for all the children was $17 \pm 7.7 \mathrm{~g}$. Multiple regression analysis revealed that 24 months after diagnosis, the body fatness of males or females was not correlated to dietary fat intake $1000 \mathrm{kcal}^{-1}$, total energy intake or glycaemic control, but there was a positive correlation $(p=0.05)$ between the consumption of saturated fat $\left(\% \mathrm{kcal}^{-1}\right)$ and dose of insulin (U $\left.\mathrm{kg}^{-1}\right)$.

\section{Dietary adherence in relation to glycaemic control}

Since there were no significant differences in the mean intake of macronutrients (carbohydrates, fat and protein) at the three time-points studied, these intakes for each child were averaged for the total 12 days of recording (Table 5). The mean intake of carbohydrates was lower than recommended in the group of children demonstrating $\mathrm{HbA}_{1 \mathrm{c}}$ values of

Table 4. Body mass index (BMI) of children with diabetes in relation to the marital situation of their parent(s)

\begin{tabular}{lllll}
\hline & \multicolumn{4}{l}{ Time after diagnosis (months) } \\
\cline { 2 - 5 } Parental situation & 0 & 6 & 12 & 24 \\
\hline Single parent $(n=6)$ & $18.3 \pm 2.1$ & $19.0 \pm 2.3$ & $19.3 \pm 2.8$ & $20.1 \pm 3.5$ \\
Married/cohabiting $(n=32)$ & $16.2 \pm 2.0$ & $17.0 \pm 1.6$ & $17.3 \pm 1.8$ & $18.2 \pm 2.1$ \\
$P$-Value & 0.03 & 0.01 & 0.03 & 0.02 \\
\hline
\end{tabular}

Data are shown as mean + SD.

The children of single parents exhibited significantly higher BMI values (Student's $t$-test), with no difference in the mean age ( 9 years) at the time of diagnosis.
Table 5. Mean daily intake of various nutrients in children with diabetes compared with the recommended intakes at the time of the study and glycaemic control (expressed as mean $\mathrm{HbA}_{\mathrm{Ic}}$ value in $\% 5$ years after diagnosis)

\begin{tabular}{|c|c|c|c|c|}
\hline \multirow[t]{3}{*}{ Nutrient } & \multirow{3}{*}{$\begin{array}{l}\text { Recommended } \\
\text { intake }\end{array}$} & \multicolumn{2}{|c|}{ Actual intake } & \multirow[b]{3}{*}{$P$} \\
\hline & & \multicolumn{2}{|l|}{$\mathrm{HbA}_{\mathrm{Ic}} \%$} & \\
\hline & & $\begin{array}{l}<8.3 \\
(n=27)\end{array}$ & $\begin{array}{l}>8.3 \\
(n=7)\end{array}$ & \\
\hline Carbohydrate (E\%) & $50-55$ & $51.0 \pm 4.2$ & $48.6 \pm 3.6$ & ns \\
\hline Sucrose $(g)$ & & $17.3 \pm 1.6$ & $16.3 \pm 2.4$ & ns \\
\hline Protein $(E \%)$ & $15-18$ & $15.5 \pm 1.6$ & $15.9 \pm 0.9$ & ns \\
\hline Fat $(E \%)$ & $30-35$ & $30.5 \pm 3.3$ & $32.8 \pm 3.0$ & 0.003 \\
\hline Saturated fat $(E \%)$ & $<10$ & $13.3 \pm 1.9$ & $14.1 \pm 2.5$ & ns \\
\hline Cholesterol (mg day ${ }^{-1}$ ) & $<300$ & $246 \pm 73$ & $277 \pm 71$ & ns \\
\hline Fibre $\left(\mathrm{g} \mathrm{day}^{-1}\right)$ & $>20$ & $19.7 \pm 4.6$ & $18.9 \pm 6.2$ & ns \\
\hline Vitamin D $\left(\mu \mathrm{g}\right.$ day $\left.^{-1}\right)$ & 10 & $6.1 \pm 1.8$ & $6.4 \pm 1.4$ & ns \\
\hline Vitamin E (mg day $\left.{ }^{-I}\right)$ & 7 & $6.7 \pm 2.1$ & $7.8 \pm 2.2$ & ns \\
\hline Zinc $\left(\mathrm{mg}\right.$ day $\left.^{-I}\right)$ & 10 & $10.7 \pm 2.2$ & $11.5 \pm 2.8$ & ns \\
\hline
\end{tabular}

Data are shown as mean \pm SD.

Values are based on the averages for each child for all 12 days of dietary recording, i.e. 4 days each 6,12 and 24 months after diagnosis.

$\mathrm{HbA}_{\mathrm{Ic}}$ : major fraction of glycosylated haemoglobin; $E \%$ : percentage of total energy intake; ns: no significant difference between the two groups.

$>8.3 \% 5$ years after diagnosis. These same children exhibited a significantly higher intake of fat than did children with lower $\mathrm{HbA}_{1 \mathrm{c}}$ values. There was a significant correlation between the percentage of the total energy ingested as fat and the mean $\mathrm{HbA}_{1 \mathrm{c}}$ value during year 5 after diagnosis $(p=0.003)$, but no such correlation was observed for the percentage of the total energy ingested as protein, carbohydrates or fibre. When expressed as nutrient intake $1000 \mathrm{kcal}^{-1}(=4.18 \mathrm{MJ})$, the mean percentages of the total energy ingested as C18:2 $(p=0.014)$ and polyunsaturated fat $(p=0.024)$ were significantly higher in the children demonstrating poorer glycaemic control.

The day-to-day variations in consumption of energy $(p=0.003)$ and certain nutrients (i.e. carbohydrates, polyunsaturated fat and C18:3 and C18:2 fatty acids) differed significantly between children with different degrees of glycaemic control (Table 6). Children who were 8 years or older at the time of diagnosis and demonstrated poor glycaemic control 5 years later demonstrated significantly higher variance in their day-to-day energy intake as early as 6 months following diagnosis. 
Table 6. Mean daily intake of energy and certain additional nutrients by children with diabetes compared with glycaemic control

\begin{tabular}{lccc}
\hline \multicolumn{3}{c}{ Mean HbA $\mathbf{H}_{\mathbf{l c}} \%$} & \\
\cline { 2 - 3 } & $<8.3(n=27)$ & $>8.3(n=7)$ & $P^{\mathrm{a}}$ \\
\hline Energy (kcal) & $1940 \pm 293$ & $2112 \pm 525$ & 0.003 \\
Energy (MJ) & $8.1 \pm 1.2$ & $8.8 \pm 2.1$ & \\
Carbohydrates (g) & $247 \pm 37$ & $257 \pm 72$ & 0.002 \\
Protein (g) & $76 \pm 15$ & $83 \pm 19$ & $\mathrm{~ns}$ \\
Fat (g) & $71 \pm 14$ & $82 \pm 20$ & $\mathrm{~ns}$ \\
Monounsaturated fat (g) & $26 \pm 5.2$ & $30 \pm 7.0$ & $\mathrm{~ns}$ \\
Polyunsaturated fat (g) & $11 \pm 2.4$ & $14 \pm 4.2$ & 0.008 \\
Essential fatty acids (g) & & & \\
Cl8:3, n-3 ( $\alpha$-linolenic acid) $(\mathrm{g})$ & $1.2 \pm 0.3$ & $1.5 \pm 0.5$ & 0.016 \\
Cl8:2, n-6 (linoleic acid) $(\mathrm{g})$ & $9.3 \pm 2.0$ & $11.8 \pm 3.4$ & 0.004 \\
\hline
\end{tabular}

Data are shown as mean \pm SD.

The mean values and variances are based on the averages for each child for all 12 days of dietary reporting, i.e. 4 days each 6, 12 and 24 months after diagnosis.

${ }^{a}$ Statistical comparison of the variance. The means were not significantly different, but in the case of energy and some of the nutrients, the variances (SD) of the values for the two groups were significantly different, as indicated.

$\mathrm{HbA}_{I \mathrm{c}}$ : major fraction of glycosylated haemoglobin; ns: not significant.

\section{Extra meals}

Half of the children reported no or only one extra meal (i.e. in excess of the recommended 6 meals day $^{-1}$ ), but a few reported more than 10 extra meals during the 12 days, most commonly taken at night. A higher number of extra meals, taken primarily in connection with episodes of hypoglycaemia, was correlated to lower mean $\mathrm{HbA}_{1 \mathrm{c}}$ values, measured $3(p=0.02), 4(p=0.035)$ and $5(p=$ 0.053 ) years after diagnosis. The level of the formal education of the parents showed no relationship to the number of extra meals. The fat content of these extra meals was highly variable from patient to patient (ranging from 0 to $52.7 \%$ of the total energy content of the extra meals), but was not related to age, body fat content or mean level of macronutrient intake.

\section{Fat}

The total mean \pm SD value for daily fat consumption by all of the children was $11.1 \pm 10.0 \mathrm{~g} \mathrm{day}^{-1}$. Saturated fatty acids accounted for $4.5 \pm 4.1 \mathrm{~g}$ day $^{-1}(41 \%)$, monounsaturated fatty acids for $4.1 \pm 4.3 \mathrm{~g} \mathrm{day}^{-1}(37 \%)$ and polyunsaturated fatty acids for $1.7 \pm 1.6 \mathrm{~g} \mathrm{day}^{-1}(=14 \%)$. The mean fat intake of all patients accounted for $37.1 \mathrm{~g} 1000$ $\mathrm{kcal}^{-1}$ (30.9\% of the total energy). There were no significant differences between initial programme of treatment, age or gender. However, as mentioned above, there was a statistically significant correlation between the mean $\mathrm{HbA}_{1 c}$ value determined during the fifth year after diagnosis and the percentage of the total energy derived from fat $(p=0.033)$.

\section{Discussion}

In this study, it was previously concluded that the family satisfaction with the treatment received was significantly higher in the study group (10). Two years following diagnosis the subjective emotional climate of the family was significantly improved in the case of the mothers and fathers in the study group, but not for the parents in the control group (12). It was also concluded that the long-term glycaemic control was not influenced by the initial treatment regimen. Five years after diagnosis, the overall mean $\mathrm{HbA}_{1 \mathrm{c}}$ value was $7.2 \%$, and $30 \%$ of the children had $\mathrm{HbA}_{1 \mathrm{c}}$ values of $<6.3 \%$ (19).

Dietary adherence was generally good for all groups of patients, i.e., in compliance with the SNR. The baseline nutrient intake before the dietary education of these children was not assessed; however, the intake of age- and time-comparable, healthy Swedish children 4 and 13 years of age was 37-38 $E \%$ fat, $14-15 E \%$ protein and $49-47 \%$ carbohydrates (21). This means that the fat intake of these children with diabetes seemed lower and the intake of carbohydrates higher than of healthy children. This may be due to efforts and pedagogical methods in both of the treatment groups during the initial treatment to improve knowledge and motivation with respect to the importance of diet. Another important fact is that the dietary intake was stable and 2 years after diagnosis still adherent to the recommendations. The study groups demonstrated a smaller day-to-day variation in fat intake, reflecting the information they received with extra attention paid to the quality and quantity of fat. This message was communicated to both of the treatment groups, but only the study group practised cooking with the dietician on several occasions, so that this issue was addressed repeatedly to these patients and their families.

The social tradition with regard to choice of food is a very important factor. In comparison with a recent study of the dietary intake of healthy US children, the difference is even higher (8), although US children $<10$ years of age with diabetes are reported as being adherent with nutritional recom- 
mendations (11). A tendency for, in particular, girls whose parents have a low level of formal education to accumulate a higher content of body fat was reported previously (22). In the present study significantly more body fat was observed in children with single parents, regardless of the level of parental education. Perhaps the children in these one-parent households are not encouraged as strongly to engage in physical activities as are children in two-parent households, for social, economic and practical reasons. The educational level of the parent had no apparent influence on the choice of food, except that there was a higher content of saturated fat in the diet of children with well-educated mothers. This observation is somewhat confusing, but may simply reflect lack of time available to plan meals properly.

No correlation was found between the body composition (expressed as BMI or skinfold) and the degree of glycaemic control or intake of energy and/or fat. It would have been interesting to add "physical activity" as a variable in connection with these calculations, but no such determination was performed. An earlier study involving healthy children has shown, not surprisingly, that children exhibiting habitually high physical activity tend to have less body fat than less active children, despite a higher energy intake (22).

With regard to both the daily mean intake and day-to-day variation, the consumption of fat was significantly related to poor glycaemic control. Although their values were still within the recommended limits, the group of children exhibiting poorer glycaemic control reported a higher daily intake of total fat and problems in maintaining a satisfactory day-to-day stability in the intake, which was also the case with respect to carbohydrates and glycaemic control. Large variations in eating behaviour will undermine glycaemic control unless the insulin treatment is exceptionally well adjusted. None of the patients in the present study received insulin via a pump and the study was also performed before the availability of rapidly acting insulin analogues, which facilitate blood glucose adjustment.

Although there is not yet sufficient information available to determine definitively the optimal intake of fat for children of different ages, the intake of saturated fat should not exceed $10 \%$ of the total intake of energy according to generally accepted recommendations. This recommendation, appropriate for children over the age of 3 years, is based on the repeated demonstration of an association between a high dietary intake of saturated fat and a high incidence of obesity, high blood pressure, insulin resistance, cardiovascular disease and certain types of cancer (23). This mean value for all of the patients involved here was approximately $13 \%$, but the intake of cholesterol, which, when elevated, is also associated with increased risk for cardiovascular disease, was acceptably low. High consumption of polyunsaturated fat ( $>15 \%$ of the total energy intake) can impair blood clotting and immune responses and today it is recommended that this consumption should not exceed $7-10 \%$ of the total energy intake (24), which was the case for all of the children in the current study. The variable content of polyunsaturated fat of the diet probably reflects the number of sandwiches spread with margarine.

The consumption of protein by the subjects was acceptably low ( $15 \%$ of the total energy intake), although the recommended intake in some countries today is even lower (i.e. 7-13\%) (24). Another Swedish study (25) demonstrated a protein intake by diabetic children corresponding to $18 \%$ of the total energy and more recent international comparisons report similar values of $17-20 \%(11,26,27)$. The consumption of fibre was satisfactory in all of the groups.

The positive correlation between the number of meals taken and a lower $\mathrm{HbA}_{1 \mathrm{c}}$ value was perhaps surprising. However, tighter glycaemic control correlates with more episodes of hypoglycaemia, which leads to a need for compensational behaviour. The fat content of these meals was highly variable from child to child, reflecting the habit of compensating with only rapid acting carbohydrates or an additional sandwich.

There are indications that self-reporting of dietary habits may result in an underestimation of energy intake (28), which was probably the case in the present study, since the total mean daily energy intake was lower than expected. When this study was conducted, 7 day prospective recording was considered to provide accurate reference values (29), but subsequent validation studies using doublelabelled water (DLW) suggest that no procedure for self-reporting of dietary intake can be considered valid a priori (30). The difficulties associated with self-reported dietary data highlight the distinct possibility of overinterpreting the results of a clinical investigation and conclusions must be 
drawn with caution, especially when there is a small number of participants.

With these reservations, it may be concluded that both the control and study groups complied well with the dietary guidelines formulated in the SNR, directed towards both healthy and diabetic children. In comparison with healthy Swedish and Finnish children, the consumption of fat was lower and that of carbohydrates higher. A positive fact was also that the children maintained their recommended dietary intake during the 2 years after diagnosis. The treatment regimen of the study group, combining an accurate dietary education with milieu and family therapeutic support, showed encouraging results with less day-to-day variation in the intake of polyunsaturated fat. The home-like environment of the training apartment made it possible to illustrate the eating customs of the child and family, and permitted an individual nutritional education with behaviour modification if necessary. In addition to the other proven advantages, the environment of the training apartment permits individualized and problem-based dietary learning systems.

Children demonstrating poor glycaemic control had a significantly higher mean intake of total fat than children with better glycaemic control. The former patients also exhibited larger day-to-day variations in their intake of total energy, carbohydrates and polyunsaturated fat.

Because of the proven linkage to cardiovascular diseases and early death, the importance of the quantity and quality of dietary fat must be emphasized even more in diabetes information and education, especially for those children with poor metabolic control.

\section{Acknowledgements}

This investigation was supported by grants from the Dalarna Research Council and Barndiabetesfonden.

\section{References}

1. Diabetes Control and Complications Trial Research Group. Effect of intensive diabetes treatment on the development and progression of long-term complications in adolescents with insulin-dependent diabetes mellitus. J Pediatr 1994; 125: 177-88.

2. Valsania P. Severity of coronary artery disease in young patients with insulin-dependent diabetes mellitus. Am Heart J 1991; 122: 695-700.
3. Kinmonth AL, Magrath G, Reckless JPD. Dietary recommendations for children and adolescents with diabetes. Diabetic Medicine 1989; 6: 537-47.

4. Ha TK, Lean ME. Recommendations for the nutritional management of patients with diabetes mellitus. Eur $\mathbf{J}$ Clin Nutr 1998; 52: 467-81.

5. Lichtenstein AH, Kennedy E, Barrier P, Ernst ND, Grundy SM. Dietary fat consumption and health. Nutr Rev 1998; 56: 3-28.

6. Rudberg S, Dahlqvist G, Aperia A, Persson B. Reduction of protein intake decreases glomerular filtration rate in young type 1 (insulin-dependent) diabetic patients mainly in hyperfiltering patients. Diabetologia 1988; 31: 878-83.

7. Pecis M, Acevedo M, Gross J. Chicken and fish diet reduces glomerular hyperfiltration in IDDM patients. Diabetes Care 1994; 17: 665-72.

8. Munoz KA, Krebs-Smith SM, Ballard-Barbash R, Cleveland L. Food intake of US children and adolescents compared with recommendations. Paediatrics 1997; 100: 323-9.

9. Waldron S, Swift PGF, Raymond NT, Botha JL. A survey of the dietary management of children's diabetes. Diabetic Medicine 1997; 14: 698-702.

10. Forsander G. Family attitudes to different management regimens in diabetes mellitus. Pract Diabetes Int 1995; 12: $80-55$.

11. Randecker GA, Smiciklas-Wright H, McKenzie JM, Shannon BM, Mitchell DC, Becker DJ, et al. The dietary intake of children with IDDM. Diabetes Care 1996; 19: 1370-4.

12. Forsander G, Sundelin J, Persson B. Influence of the initial management regimen and family social situation on glycemic control and medical care in children with type I diabetes mellitus. Acta Paediatr 2000; 89: 1462-8.

13. Marshall WA, Tanner JM. Variation in the pattern of pubertal changes in girls. Arch Dis Child 1969; 44: $291-$ 303.

14. Marshall WA, Tanner JM. Variations in the pattern of pubertal changes in boys. Arch Dis Child 1970; 45: $13-$ 23.

15. Roche AF, Siervogel RM, Chumlea WC, Webb P. Grading body fatness from limited anthropometric data. Am J Clin Nutr 1981; 34: 2831-8.

16. Slaughter MH, Lohman TG, Boileau RA, Horsewill CA, Stillman RJ, van Loan MD, et al. Skinfold equations for estimation of body fatness in children and youth. Hum Biol 1988; 60: 709-23.

17. Norbrink B. Seqla- Extern kvalitetssäkring genom kartläggning av skillnader. Läkartidn 1996; 93: 541-2, 547.

18. Snellman K, Eckerbom S. Possibilities and advantages with home sampling of $\mathrm{HbA}_{1 \mathrm{c}}$ : eight years experience. Diabetic Medicine 1997; 14: 401-3.

19. Forsander G, Persson B, Sundelin J, Berglund E, Snellman K, Hellström R. Metabolic control in children with insulin-dependent diabetes mellitus 5 years after diagnosis. Early detection of patients at risk for poor metabolic control. Acta Paediatr 1998; 87: 857-64. 
20. Norusis MJ/SPSS. SPSS for Windows, Advanced statistics Release 6.0. Chicago, IL: SPSS.

21. Samuelson G. Kostvanor idag hos barn i Sverige och Finland. Näringsforskning 1988; 2: 77-80.

22. Sunnegårdh J, Bratteby L-E, Hagman U, Samuelson G, Sjölin S. Physical activity in relation to energy intake and body fat in 8- and 13-year-old children in Sweden. Acta Paediatr Scand 1986; 75: 955-63.

23. Hernell $\mathrm{O}$. The role of dietary fat in infants and children. Rev Ser Pediatr 2000; 2: 2-5.

24. Pinelli L. Diet in childhood diabetes. Acta Paediatr Suppl 1998; 425: 47-9.

25. Arvidsson Lenner R, Carlgren G, Hardell L-I, Johansson B, Jonsson G, Samuelson G, et al. Food and nutrient intake in Swedish diabetic children. Näringsforskning 1989; 33: 149-53.

26. Dorchy H, Bourguet K. Nutritional intake of Belgian diabetic children. Diabetes Care 1997; 20: 1046-7.

27. Virtanen S, Ylönen K, Räsänen L, Ala-Venna E, Mäenpää J, Åkerblom H. Two year prospective dietary survey of newly diagnosed children with diabetes aged less than 6 years. Arch Dis Child 2000; 82: 21-6.
28. Merz W, Tsui JC, Judd JJ, Reiser S, Hallfrish J, Morris $\mathrm{E}$, et al. What are people really eating? The relation between energy intake derived from estimated diet records and intake determined to maintain body weight. Am J Clin Nutr 1991; 54: 291-5.

29. Blom L, Lundmark G, Dahlqvist G, Persson LÅ. Estimating children's eating habits. Validity of a questionnaire measuring food frequency compared to a 7day record. Acta Paediatr Scand 1989; 78: 858-64.

30. Bratteby L-E, Sandhagen B, Enghardt H, Fan H, Samuelson G. Validity of dietary intake measurements in adolescents. Three validation studies. Scand J Nutr 1998; 42: 29-30.

\section{Gun Forsander}

Division of Diabetes

The Queen Silvia Children's Hospital

SE-4I 685 Göteborg

Sweden

E-mail: gun.forsander@vgregion.se 